\title{
TIEMPO Y PERSPECTIVA EN LA PELÍCULA RASHOMON DE AKIRA KUROSAWA
}

\section{TIME AND PERSPECTIVE ON FILM AKIRA KUROSAWA'S RASHOMON}

\begin{abstract}
AUTOR/ES
María del Mar Grandío Pérez: Profesora contratada. Doctora de la Facultad de Ciencias Sociales y de la Comunicación. Universidad Católica San Antonio de Murcia. Murcia (España).

MGrandio@pdi.ucam.edu
\end{abstract}

\section{RESUMEN}

El objetivo de este artículo es analizar el papel del tiempo y de la subjetividad de las perspectivas en la película Rashomon, aspectos que se consideran decisivos en la filmografía de Akira Kurosawa. En concreto, se pretende poner en evidencia la utilización del multiperspectivismo y los flashbacks con la intención de transmitir la insinceridad de los relatos articulados de la película. En primer lugar y a modo de contextualización, este artículo contextualizará el impacto internacional que tuvo esta obra en el momento de su estreno analizando la cobertura que la prensa europea y americana hizo sobre la película y la obra de Kurosawa. Ejemplificará la recepción de Rashomon por parte de un colectivo con bastante influencia sobre el público general. La parte principal del artículo analiza el tratamiento del tiempo en este filme, para terminar ofreciendo algunas reflexiones sobre el conocimiento de la verdad cuando las narraciones son "mentirosas", la gran pregunta latente en el texto fílmico de Kurosawa.

\section{PALABRAS CLAVE}

Tiempo - Perspectiva - Rashomon - Akira Kurosawa

\section{ABSTRACT}

The aim of this paper is analyzing the role of time and subjectivity of perspectives in Kurosawa's Rashomon. It is intended to underline the use of flashbacks and multiperspectivism to convey the insincerity of articulated narratives in the film. First of all, this article will contextualize the international impact of this film when its release analyzing the coverage of some European and American newspapers about and Kurosawa's work. The main part of the article will examine the concept of time in this film. It will conclude offering some thought about the knowledge of the truth when the stories are "lies", the big question in the Kurosawa's film text. 


\title{
KEY WORDS
}

Time - Perspective - Rashomon - Akira Kurosawa

\section{ÍNDICE}

\author{
$\boldsymbol{\omega}$ 1. INTRODUCCIÓN \\ $\boldsymbol{\omega}$ 2. LA RECEPCIÓN DE RASHOMON POR LA CRÍTICA DE OCCIDENTE \\ $\boldsymbol{\sim}$ 3. ANÁLISIS DE RASHOMON \\ 3.1 Tiempo y espacio en Rashomon \\ 3.2 Multiperspectivismo de la historia y articulación de los flashbacks \\ 3.3 Última escena y ¿redención final? \\ 4. A MODO DE CONCLUSIÓN: REFLEXIONES EN TORNO AL \\ CONOCIMIENTO DE LA VERDAD Y LAS “NARRACIONES MENTIROSAS" \\ 5. BIBLIOGRAFÍA \\ 6. CRÍTICAS EN LA PRENSA \\ 7. ANEXO 1: FICHA DE LA PELÍCULA
}

\section{INTRODUCCIÓN}

\author{
"Men are weak and they lie, even to themselves" \\ Rashomon, 1950
}

\footnotetext{
"Rashomon. It's more than just a movie. The word has come into a language now"
} Fay Kanin, co-autor de una adaptación de Rashomon en 1959

Kioto siglo XII. Las ruinas del antiguo templo de Rashomon están siendo azotadas por una fuerte tormenta. Dentro del santuario, un sacerdote, un leñador y un peregrino se guarecen de la lluvia mientras intentan comprender el inquietante acontecimiento que ha ocurrido recientemente en un bosque cercano: una mujer ha sido violada y su marido asesinado por razones desconocidas. Los hechos acaecidos no son fáciles de entender. Las declaraciones de los cuatro implicados en el homicidio desfilan en un juicio cuyo máximo juez es una cámara cinematográfica- y por extensión el espectador- y en el que la verdad queda escondida y manipulada constantemente por los declarantes. La acción retrocede cuatro veces en el tiempo para escuchar a los implicados contar el mismo hecho desde sus diferentes perspectivas, algo que no hace más que añadir incertidumbre a los tres personajes guarecidos en el templo de Rashomon y que intentan dilucidar la verdad sin lograrlo. Las versiones de los testigos son contradictorias. Todo apunta a que alguno de los implicados -o tal vez todos- esté mintiendo. ¿Qué es lo que ha ocurrido exactamente en el bosque? ¿Quién de ellos miente? ¿Es que acaso nadie dice la verdad? 
Este atractivo argumento inicial bien podría ser el comienzo de un blockbuster judicial o un reciente thriller americano. Sin embargo, puede sorprender al espectador medio del siglo XXI que este planteamiento sea el arranque de una película del año 1950 titulada Rashomon, del director japonés Akira Kurosawa y que es, además, una adaptación literaria de dos relatos literarios. Esta película representa la universalidad, tanto geográfica como temporal, de la obra del japonés Kurosawa. En el fondo, de la universalidad y potencialidad del lenguaje audiovisual.

Una de las cuestiones más interesantes de Rashomon y que llamó desde el principio la atención de la crítica especializada es cómo estaba contada la historia. Es concreto, la experimentación del tiempo cinematográfico y de la perspectiva. En la década de los 50, este filme se asoció principalmente con la más arriesgada de las vanguardias por el uso revolucionario de una narración basada en múltiples enfoques. Estaba contada a través de varios flashbacks que ponían en evidencia cómo las particulares miradas de los personajes sobre un mismo hecho no contenían la verdad de lo ocurrido. Es decir, se ponía en tela de juicio lo mostrado visualmente por la cámara ya que los relatos contados estaban manipulados por los intereses de sus emisores.

Sin embargo, el lenguaje audiovisual perdería toda su fuerza si nos encontráramos únicamente ante fuegos de artificio, innovación visual y experimentación sin un trasfondo, algo que, por otro lado, ocurre en demasiadas ocasiones en los productos audiovisuales actuales. No es el caso de Rashomon. En concreto, este uso del tratamiento del tiempo tan rompedor en su momento está al servicio de la transmisión de una profunda realidad: la descripción de la compleja naturaleza humana, que se muestra a la audiencia la mayor parte de la película ambigua, egoísta, y en la que la verdad queda corrompida constantemente por quien habla.

Rashomon es una entrada para el disfrute cinematográfico con una historia excelentemente construida, una invitación para que el espectador reflexione sobre su propia existencia y, al mismo tiempo, un reto para la interpretación filosófica. Rashomon nos interpela: ¿Cómo podemos juzgar un evento cuando las historias sobre los hechos están llenas de ambigüedades? ¿Se puede conocer la verdad de las acciones a través de las narraciones? ¿Es el hombre incapaz de decir la verdad? ¿Es más fuerte el egoísmo y el beneficio propio que el amor a la verdad? Kurosawa, como buen artista, plantea más preguntas con su obra que parece ofrecer repuestas y encumbra a Rashomon, como todo buen cine, a ser una pregunta abierta, siempre provocativa, a los ojos del espectador inquieto de todos los tiempos, ansioso de buscar respuestas y sentido a su existencia. En general, el conjunto de la obra de Kurosawa es una constante meditación sobre la compleja dualidad de los seres humanos, capaces del mal, pero también de obrar el bien. Este es, probablemente, su gran logro y una de las razones por la que se le considera ya un clásico.

Mucho se ha hablado sobre la relevancia de Rashomon en la filmografía de Kurosawa y en la Historia del Cine, sobre todo, por ser la auténtica piedra angular de la 
entrada del cine asiático en Occidente. Gran parte del interés que despertó esta película en Occidente viene dado sobre todo por este estupendo manejo del lenguaje audiovisual para trasmitir las contradicciones del ser humano, algo que da a la obra de Kurosawa ese sello artístico incuestionable a la vez que humanista. Como diría Fay Kanin, coautor de una adaptación de este film en 1959: “Rashomon es más que una película. La palabra se ha convertido ahora en lenguaje" 1 .

En concreto, el centro de este artículo es la reflexión sobre el papel del tiempo y de la subjetividad de las perspectivas en Rashomon, aspectos que se consideran decisivos en la filmografía de Kurosawa y que explicarían su influencia en obras fílmicas de autores tan dispares como Kubrick (Atraco perfecto), Alan Resnais (Muriel) o Bryan Singer (Sospechosos habituales). La intención de un estudio sobre el tiempo no es otro que poner en evidencia la utilización del multiperspectivismo y los flashbacks para transmitir la insinceridad de los relatos articulados de la película. En primer lugar y a modo de contextualización, nos acercaremos al impacto internacional que tuvo esta obra en el momento de su estreno analizando la cobertura que la prensa europea y americana hizo sobre la película y la obra de Kurosawa. Ejemplificará la recepción de Rashomon por parte de un colectivo con bastante influencia sobre el público general. Después, se pasará a analizar el tratamiento del tiempo en este filme, para terminar ofreciendo algunas reflexiones sobre el conocimiento de la verdad cuando las narraciones son "mentirosas", la gran pregunta latente en el texto fílmico de Kurosawa.

\section{LA RECEPCIÓN DE RASHOMON POR LA CRÍTICA DE OCCIDENTE}

Akira Kurosawa es, sin lugar a dudas, el director japonés más conocido fuera de su país. Tal vez, sin el éxito internacional de este director, el cine japonés no gozaría de su reconocimiento y prestigio actual. La industria cinematográfica japonesa se dio cuenta de la potencialidad de sus obras en el mercado internacional ${ }^{2}$, siendo Rashomon así una pieza clave de la denominada Época Dorada del Cine Japonés.

El lanzamiento internacional de Rashomon se produjo al obtener el Gran Premio a la mejor película en el Festival Internacional de Cine de Venecia en 1951. Su consagración como director revelación en occidente vino ese mismo año cuando la Meca del Cine, en concreto The National Board of Review, premió a Kurosawa como mejor director y a Rashomon como mejor película extranjera. En 1952 el trabajo de Kurosawa había sido reconocido tanto por los críticos europeos como estadounidense. Se puede decir que había conquistado occidente. Paradójicamente, Kurosawa ya había sido despedido por los estudios Daiei cuando las noticias del triunfo de Rashomon en Venecia llegaron a Japón. En aquel momento se pensó que la película iba ser "muy difícil de entender" 3 .

${ }^{1}$ Cfr. "Rashomon returns, probing reality anew". The New York Times, 20 de marzo de 1988.

2 Cfr. YOSHIMOTO, M. (2000): Kurosawa Film Studies and Japanese Cinema. Durham: Duke University Press, p. 1.

${ }^{3}$ Cfr. "Kurasawa, Samurai of the Cinema". The Washington Post. 4 de julio de 1982. 
Como adelantábamos, interesa descubrir en este apartado cómo recogió la prensa especializada el trabajo de Kurosawa y la relevancia de la película de Rashomon en el momento de su estreno y con posterioridad. Abordaremos el conjunto de críticas aparecidas, sobre todo, en medios americanos y europeos. De esta forma, la descripción presentada incluirá lo que han opinado este grupo de profesionales que tanta influencia tienen sobre el público en general.

Para ello, se ha recogida una muestra de artículos en los que se hacía referencia a Kurosawa y Rashomon (25 artículos de The New York Times, 20 artículos de The Washington Post y 11 críticas de otros medios como Cahiers du Cinema). La muestra abarca artículos de prensa recogidos desde 1951, año en el que la película triunfó en dos festivales, y se alarga hasta el año 2006. De esta manera, serán un buen ejemplo de la evolución y la crítica del trabajo de Kurosawa durante toda su trayectoria e, incluso, después de su muerte. Una mirada, por tanto, a las cuestiones que desde el punto de vista de la crítica especializada internacional eran y son relevantes en la obra del director japonés y por las que se le llegó a calificar pronto como "El emperador japonés del cine 4 " o "El Samurái del Cine ${ }^{5 \prime}$.

Rashomon, como diría más tarde Kurosawa en su autobiografía, "fue como echar

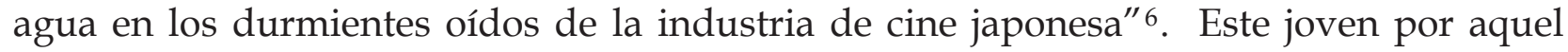
entonces director era, a los ojos de la crítica del momento, un desconocido pero sugerente cineasta que manejaba a la perfección el lenguaje audiovisual a la vez que planteaba temáticas complejas que fomentaban el debate entre los cinéfilos. Para Richard Griffit, una de las características más interesantes de Rashomon en 1951 era la propia historia relatada, "universal e intemporal", y destacaba la excelente interpretación de los actores: "es como el cine mudo, cuando realmente vemos lo que ha ocurrido, la narración verbal es abandonada y la cámara habla como sólo ella puede ${ }^{7 "}$. Rashomon tiene para la crítica del momento una gran atracción audiovisual: "gran parte la fuerza de esta película- y de su incuestionable poder hipnótico, se deriva de la brillante trabajo de cámara del Director Akira Kurosawa. La fotografía es excelente y el flujo de las imágenes es expresivo más allá de las palabras. Además, el uso de la música y del sonido es excelente, y las actuaciones de todos los actores son aptamente provocativas" ${ }^{8}$. En palabras de otro crítico, este manejo de la cámara tiene una influencia del naturalismo japonés "en una combinación de estilo realista y tradicional, extrañamente entretenido, y fuertemente afectivo $^{9 \prime}$. Pero sobre todo y por encima del manejo audiovisual, la crítica del momento destacó ampliamente el gran humanismo que encerraba la película. Como dice este crítico de Cahiers du Cinema en 1953: “Quién quiera que sea Akira Kurosaka ha conseguido convertirse en algo grandioso como director de cine por más cosas que el

\footnotetext{
${ }^{4}$ Cfr. "Japan's Emperor of Film", New York Times. 29 de octubre de 1989.

${ }^{5}$ Cfr. "Kurasawa, Samurái of the Cinema". Washington Post. 4 de julio de 1982.

${ }^{6}$ Cfr. "Look for me in my film". New York Times: 27 de junio de 1982.

7 Cfr. GRIFFITH, R. Saturday review. 12 de enero de 1952.

8 Cfr. CROWTHER, B., The New York Times. 27 de diciembre de 1951.
} 
conocimiento de las lentes y su cámara. Él sabe lo difícil que es vivir, y cuán necesario amar".

La extrañeza ante el relato junto, la admiración por el lenguaje audiovisual empleado y su fuerte humanismo fue constante en las críticas de la época. Por supuesto, no todo fueron comentarios positivos. Se encuentra alguna crítica negativa que apuntaba a que era una película "vacía, lenta y demasiado pretenciosa"10, "un popurrí japonés sin demasiado entretenimiento" 11 y que la escena en la que aparecía un bebé abandonado en el templo sobraba12. Otros señalan a la película como una "interesante curiosidad cinematográfica" aunque pensaban también que la última escena era arbitraria y que no mantenía relación alguna con el resto de la historia ${ }^{13}$. En Francia, Cahiers $d u$ Cinema en 1953 recoge la enorme controversia que suscitó la película en el país para concluir, "las conclusiones de este autor japonés tienen un alto valor humanístico. La forma de una película solamente merece la pena cuando se adapta adecuadamente a un contenido de calidad. Y esto ocurre en Rashomon ${ }^{14 " .}$

Los premios cosechados junto con el caluroso recibimiento por la crítica hicieron que Kurosawa fuera pronto admirado por cineastas de todo el mundo. El éxito en Europa y Estados Unidos de la película le permitió a Kurosawa también ganar el reconocimiento de sus propios compatriotas, de aquellos que no confiaron en su arte en los inicios. Sería el precursor de la denominada Década de Oro del Cine Japonés, en la década de los 50. Una época en la que los grandes estudios permitían a directores como Kurosawa hacer la película que ellos deseaban con bastante libertad. Según Kurosawa, el hacer fílmico propio de occidente era lo que realmente daba validez comercial a las obras audiovisuales, siendo ésta la clave para el lanzamiento de una verdadera industria del cine en Japón. En declaraciones para el The Washington Post en 1952, el propio Kurosawa afirmaba que "si las producciones japonesas son lo suficientemente buenas siguiendo los estándares occidentales para ganar dólares, nosotros intentaremos hacer más películas como Rashomon"15. Sin embargo, desde el principio tuvo claro que eso no significa imitar las películas de directores americanos o europeos. Al contrario, consideraba que el cine japonés necesita encontrar su propio estilo genuinamente japonés ya que "si queremos estar en primera línea, debemos desarrollar una escuela propia".

A partir de 1952, se relaciona a Kurosawa con la película que le catapultó a la fama en occidente, siendo Rashomon referencia indiscutible cuando se nombra a este cineasta en la prensa. Muchos artículos definen generalmente a Kurosawa como "el director de Rashomon" para presentarle en sus escritos. En 1954 Ray Falk, enviado especial a Tokio para cubrir el South East Film Festival, destaca en su crónica que el cine asiático quiere ser visto en todo el mundo tras la senda abierta con Kurosawa, y subraya, "el

10 Cfr. FARVER, M.; The Nation. 12 de enero de 1952.

11 Cfr. McCARTEN, J., The New Yorker. 29 de diciembre de 1951.

12 Cfr. "Rashomon and the fith Witness", The Hudson Review, 5(3), 1952.

13 Cfr. "Rashomon". Time. 7 de enero de 1952.

14 Cfr. MERCIER, P., Cahiers du Cinéma. 24 de junio de 1953. 
impresionante futuro de Kurosawa" en el panorama cinematográfico internacional16. Por su parte, Robert Hawkins, enviado a Venecia para cubrir el Festival Internacional en 1957, destaca de Kurosawa y de su película Trono de Sangre: "el director de Rashomon aplica exitosamente su estilo empático en una adaptación del Macbeth de Shakespeare, extraña y físicamente fascinante más que cerebral17". La prensa se vuelve asidua en reflejar las nuevas obras de Kurosawa como Trono de sangre ${ }^{18}$, Los bajos fondos (Donzoko) en $1957^{19}$ o La fortaleza escondida en $1958^{20}$.

Con el paso del tiempo, Rashomon se recuerda por su contenido y por la revolución formal que supuso en su momento. Es ya "una clásica exploración de la auto decepción humana y de la relatividad de la verdad 21 " o "la demostración de que la verdad de un hombre es una ficción para otro". Otras críticas resaltan cómo "las verdades universales no son tan creíbles" 22 y que "la suma de los hechos no se suman para encontrar la verdad $^{23 "}$. El propio Kurosawa recuerda en el epílogo de su autobiografía con algo de resentimiento cuando, años después, escuchó una entrevista del director de la productora Daiei en la televisión, el día en el que se iba a emitir por primera vez por la televisión Rashomon. Este extracto aparece en una reseña de autobiografía aparecida en The New York Times' ${ }^{24}$

"No me lo podía creer. Este hombre, después de mostrar tanto desagrado con el proyecto desde el comienzo de la producción, después de quejarse de que el final de la obra era "incomprensible". Después de degradar al ejecutivo de la compañía y al productor que la hizo posible, ahora él está orgulloso de llevarse todo el crédito. Se jactaba de cómo la cámara por primera vez en la historia del cine había apuntado directamente al sol. En ningún momento de su discurso mencionó mi nombre o el del director de fotografía que había consigue este hecho, Miyagawa Kazuo. Al ver la entrevista por televisión, tuve la sensación de volver a Rashomon una vez más. Era como si la patética desilusión del ego, esas deficiencias que había intentado reflejar en la película, se mostraban ahora en la vida real. La gente de hecho tiene inmensas dificultades en hablar sobre ellos mismos como realmente son. Me recordó que el ser humano sufre de un instintivo auto-engrandecimiento" (Traducción propia).

Tras el estreno de Rashomon y hasta nuestros días, han sido muchas las películas que han utilizado esta narrativa no linear a través de la utilización de múltiples perspectivas para contar sus relatos, lo que se ha denominado "efecto Rashomon" (curiosamente también se utiliza este nombre en otros ámbitos, como es el psiquiátrico, para reflejar cuando, por ejemplo, diferentes testigos de un mismo hecho dan interpretaciones subjetivas del mismo). Recordamos aquí un remake americano de

\footnotetext{
16 Cfr. "Jottings on Japan's Screen Scene". The New York Times: 30 de junio de 1954.

17 Cfr. "Venice Festival in Retrospect". The New York Times: 15 de septiembre de 1957.

18 Cfr. "Screen: Change in Scene". The New York Times, 23 de noviembre de 1961.

${ }_{19}$ Cfr. "Screen: Kurosawa's Lower Depths". The New York Times. 10 de febrero de 1962.

20 Cfr. "Screen: Hidden Fortress' From Japan". The New York Times. 24 de enero de 2962.

${ }^{21}$ Cfr. "Akira Kurosawa and his mountain of memories". The Washington Post. 14 de septiembre de 1990.

${ }^{22}$ Cfr. "The Setting Sun of Akira Kurosawa". The Washington Post. 28 de diciembre de 1993.

${ }^{23}$ Cfr. "When facts don't up to the Truth". The New York Times. 25 de mayo de 1986.
} 
Rashomon titulada Judgment in the Sun con el mismo argumento pero ambientado la Arizona (Estados Unidos) del Siglo XIX: un hombre muere en circunstancias violentas y cuatro personas dan su versión de lo ocurrido. En declaraciones del propio director del filme, Martin Ritt, la idea de Rashomon seguía totalmente pertinente 13 años después del estreno de la película original: "Necesitamos recordar que la verdad es una cuestión muy complicada, que depende de quién la vea, bajo qué circunstancias y cuáles son las suyas propias. Si los hombres son de buena voluntad, saben que hay otras verdades además de las que ellos sostienen" 25 . El "efecto Rashomon" también se puede ver en otras películas. Es el caso de Atraco Perfecto (Kubrick, 1956), Muriel (Resnais, 1963), Sospechosos Habituales (Singer, 1995), Snake Eyes (De Palma, 1998) o En el punto de Mira (Travis, 2008), entre otros filmes.

\section{ANÁLISIS DE RASHOMON}

Pasamos a continuación a analizar la película, no sin antes dar algunas pequeñas referencias técnicas sobre ella. Rashomon (1950) está basado en dos cuentos de Ryonosuke Akutagawa del siglo XXII26. El título de la película y el templo donde se desarrolla la acción (El templo de Rashomon) fueron adaptados del relato Rashomon: la puerta del diablo. Casi todo lo demás está adaptado de otro relato corto del mismo Akutagawa titulado En el Bosque. La película fue estrenada en Japón en 1950, y llegó a Europa a través del Festival Internacional de Venecia en 1951.

\subsection{TIEMPO Y ESPACIO EN RASHOMON}

La preocupación de Kurosawa por la representación del tiempo cinematográfico se materializó en Rashomon. La película comienza con una escena en el templo de Rashomon mostrando el desconcierto de un leñador y un sacerdote hablando sobre unos extraños acontecimientos que han ocurrido recientemente. "No entiendo, no entiendo", repite constantemente un leñador conmocionado. El sacerdote replica que "nunca ha escuchado una historia tan extraña" y que esta vez es posible que haya perdido su fe en la humanidad". Una tercera persona que entra en el templo para guarecerse de la fuerte lluvia, les pide que le cuenten que ha ocurrido. Es entonces cuando comienzan los saltos en el tiempo y el desfile de declaraciones. Es importante resaltar la función tan importante de la figura del peregrino en la historia ya que es a él a quien le cuentan la historia del asesinato del samurái y por el que, por tanto, el espectador puede conocer también la historia. Sin alguien a quien contar la historia, en este caso el peregrino, no conoceríamos el relato.

En este punto, hay que diferenciar la existencia de cuatro conceptos diferenciados de tiempo que se van a utilizar en este análisis: tiempo real, tiempo cinematográfico,

${ }^{25}$ Cfr. "Hollywodd new look. Rashomon altered in Time. The New York Times.19 de enero de 1964. 
tiempo presente y tiempo pasado. El tiempo real es el tiempo de la realidad del espectador, siempre lineal, y se puede alargar, acortar e incluso cambiar el orden a través de recursos audiovisuales como la elipsis o los flashbacks creando así, un nuevo concepto de tiempo: el tiempo cinematográfico. Éste determina cómo está contada esa historia y estructura el total de la narración, desde la duración de los planos o de las escenas hasta los saltos en tiempo. En este parte, es muy importante la labor de edición y montaje. Por otro lado, tiempo presente del film es el tiempo en el que se desarrolla las acciones principales de la película. Tiempo pasado son las acciones acontecidas con anterioridad a esa acción principal.

En el caso de Rashomon, un acontecimiento es el centro de atención: la muerte de un samurái que viajaba por el bosque y la violación de su mujer. Este hecho ocurre en un tiempo pasado, ya que el tiempo presente e inicio de la película como vemos en la primera escena es el templo de Rashomon, donde dos testigos del juicio (el leñador y sacerdote) cuentan a un peregrino su desconcierto por los hechos acaecidos. La cámara traslada a los espectadores a dos espacios físicos del pasado más: el juicio y el bosque donde ocurrió el asesinato, siempre a través de los flashbacks. Pero la película siempre vuelve al templo de Rashomon, también en la última escena, que es el tiempo presente del filme como decimos. El orden de los sucesos acaecidos en la película, que no de la estructura de película, quedaría como sigue expuesto cronológicamente:

Tabla 1: Orden cronológico real de los acontecimientos en la película

\begin{tabular}{|l|l|l|}
\hline PASADO I & PASADO II & PRESENTE \\
\hline $\begin{array}{l}\text { Un samurái aparece } \\
\text { asesinado en el bosque } \\
\text { en el bosque y su mujer } \\
\text { ha sido violada }\end{array}$ & $\begin{array}{l}\text { Juicio sobre los hechos } \\
\text { ocurridos en el bosque }\end{array}$ & $\begin{array}{l}\text { Conversación de dos } \\
\text { testigos del juicio } \\
\text { (leñador y sacerdote) en } \\
\text { el templo de Rashomon } \\
\text { con el peregrino }\end{array}$ \\
\hline
\end{tabular}

Pero estos acontecimientos no se muestran de manera lineal en Rashomon. La película está articulada a partir de las declaraciones de los testigos del suceso en el juicio que se desarrolla para encontrar al asesino (leñador, sacerdote y policía), así como de los tres personajes implicados directamente (samurái, mujer y ladrón). De esta manera, hay un total de siete declaraciones: el leñador, el sacerdote, el policía, el ladrón, la mujer, el samurái muerto (a través de una médium), y una segunda declaración del leñador cuyo primer relato inició la redacción.

Para ir relevando lo ocurrido, un conjunto de flashbacks configuran una narración no-lineal de los hechos que, además, como veremos, pronto se muestran inconsistentes al espectador. La utilización de este tipo de narrativas a través de flashbacks tiene como antecedente inmediato Ciudadano Kane (1941) de Orson Welles, aunque la novedad en Rashomon es cómo la vuelta al pasado no significaba que la historia contada en ese 
flashback sea verdadera, algo que sí ocurría en Ciudadano Kane. La acción que se desarrolla en el tiempo presente de la película remite a través de los flashbacks a lo que hemos denominado Pasado II (Véase tabla 1). Por su parte, las declaraciones que se desarrollan en el juicio remiten a lo que hemos denominado Pasado I (Véase tabla 1).

Sin embargo, estos flashbacks, que en el fondo son recuerdos insertados en la acción principal, no son una narración transparente y omnisciente de lo ocurrido, si no que están contados por testigos e implicados en el suceso. La película juega, por tanto, en un doble plano narrativo: el sacerdote y leñador cuentan al peregrino las declaraciones que a su vez ha sido narradas en el juicio y que ellos mismos han escuchado. Por consiguiente, existe una doble mediación de la narración: las declaraciones en el juicio están contadas desde la perspectiva de quien recuerda esa declaración (el leñador y el sacerdote), algo que complica, más si cabe, el descubrimiento de la verdad de los hechos. Podría resumirse como sigue:

a) Quién (el leñador o el sacerdote) recuerda lo acontecido en el juicio para contárselo al peregrino y que, por tanto, aparece siempre como primera mediación.

b) Quién hace la declaración delante del juez, es decir, qué versión de la historia es recordada. Se proporciona a través del testigo o personaje declarante en el juicio.

Al ser la película un desfile de recuerdos, pronto surge la duda sobre cuán fiables y exactos pueden ser. No es una narración directa a través de testigos presenciales de los hechos. En este sentido, la mediación más importante es la primera ya que el leñador o el sacerdote pueden estar mintiendo también al peregrino sobre lo que escucharon realmente en el juicio y, por consiguiente, que las declaraciones de los testigos implicados estén manipuladas por su percepción o interés. Sin embargo, en ningún momento del tiempo presente el sacerdote o el leñador parece contradecir lo que el otro está recordando. Asumamos, pues, que lo que estos dos personajes recuerdan es cierto para dar validez a las declaraciones del juicio desde el punto de vista analítico de este epígrafe.

Las tres primeras declaraciones se engloban en una primera batería de testificaciones cortas, que sirven para centrar la historia cronológicamente de cara al espectador. Las cuatro últimas son las que tienen más peso específico en el filme y las que ofrecerán una narración repetida del mismo hecho desde cuatro perspectivas distintas de las personas que sí han sido testigos directos del suceso, tal vez lo más sugerente de la película. Es aquí donde el espectador será también testigo ocular del asesinato y, gracias a la cámara de Kurosawa, presenciará el mismo hecho visto y alterada por la visión e intereses específicos de esas cuatro personas.

De las siete declaraciones de la película, las seis primeras ocurren durante el trascurso del juicio en el que los testigos e implicados con este hecho deben dar su versión frente a una cámara que hace la vez de juez. Es interesante la composición de las 
escenas del juicio porque siguen todas el mismo patrón con gran influencia del teatro: un único plano medio fijo, el testigo que habla lo hace mirando directamente a la cámara sobre un fondo totalmente blanco. Detrás, vemos siempre a los testigos del juicio (el leñador y el sacerdote), que al presenciar las declaraciones, pueden contárselo después al peregrino. Los testigos van variando para hacer sus declaraciones, pero todas las escenas siguen en mismo patrón y escenario. La composición de esta escena, aunque sabemos que ocurre entre los acontecimientos y la escena en las ruinas de Rashomon, evoca un escenario casi intemporal, para dar así más relevancia a la narración. La última de las declaraciones, la número siete, es la segunda declaración del leñador para verificar su segunda versión. Esta última versión no será contada en el juicio, si no que será en el templo fuera del sistema judicial.

\subsection{MULTIPERSPECTIVISMO DE LA HISTORIA Y ARTICULACIÓN DE LOS FLASHBACKS}

Pasamos a continuación a desglosar y analizar la película a través de sus saltos en el tiempo, la alteración del tiempo real más interesante de la película. Nos detendremos especialmente en las cuatro últimas declaraciones y sus respectivos flashbacks para poner de manifiesto la subjetividad de sus historias. La primera declaración y el primer flashback es el del leñador. Lo vemos en el juicio testificando frente a la cámara que hace de juez. Cuanta que lo que vio ocurrió hace tres días, cuando estaba paseando por el bosque. La cámara se traslada entonces en un segundo flashback al bosque, y vemos al leñador paseando. En una escena sin diálogos, pura visualización y únicamente acompañado por la música, se narra con imágenes cómo encontró primero el sombrero de una mujer, después la ropa de un samurái, una cuerda, y finalmente un cadáver de una persona no identificada en ese momento. El juez fuera de plano- al que el espectador no puede escuchar ni oír y que representa la propia cámara- le pregunta si había una espada, y él dice que no vio nada. Por lo tanto, este primer declarante dice ver el cuerpo, pero no presenció el asesinato o muerte de ese hombre.

Acto seguido vemos en el juicio al sacerdote en primer plano como segundo testigo. Explica que ese cuerpo muerto era el de un samurái que iba con una mujer tres días antes y que él vio mientras cruzaban un camino. Vemos en un tercer flashback al samurái y a su mujer sentada en un caballo, tal y cómo él pudo verlos. El sacerdote tampoco ha presenciado los hechos. Tras esta declaración, aparece el policía que ha apresado al presunto asesino del samurái, Tajomaru. Un cuarto flashback retrasa la acción una vez para explicar por medio de imágenes cómo apresó al asesino porque se calló del caballo cerca del río. La cuarta declaración es la del supuesto ladrón y asesino Tajomaru que interviene en dos ocasiones y con dos consiguientes saltos en el tiempo. El primero de sus flashback es para matizar que él no se calló del caballo debido a su torpeza, si no que bebió agua supuestamente envenenada por una serpiente del río y se desvaneció. Su segundo flashback es para confirmar que él fue quien mató al samurái. 
Se exponen a continuación las diferentes versiones de los testigos oculares de lo ocurrido:

a) Versión de Tajomaru. Es la primera declaración del primer testigo directo y presunto causante de la muerte de ese samurái. Se debe destacar que tanto la declaración del ladrón como la del resto de personajes alteran la narración de los hechos con el fin de protegerse o justificar su acción. De una manera muy poética, sin diálogos intradiegéticos, sólo con la fuerza de la música y las imágenes, se revela el encuentro entre ladrón y la pareja. Tajomaru estaba durmiendo bajo un árbol cuando cruzó delante de él el samurái con su mujer. El viento levantó en ese momento el velo de la mujer y él quedó prendida por ella en ese instante. Cuanta que su intención era conseguir a la mujer sin matar al hombre. Para ello, le dice al hombre que tiene escondidas unas espadas y que se las quiere vender a buen precio. Consigue llevarle a un lugar apartado y es ahí donde le ata, dice a través de una voz en off, para que la mujer lo viera de una manera ridícula. Cuando le lleva a la mujer, ésta le ve. Es entonces cuando Tajomaru abusa de ella. Ella al principio se resiste, pero él consigue sus propósitos: tener a la mujer sin matar a su marido. Sin embargo, él dice que no tenía intención de matar al marido, pero que la mujer le puso en la encrucijada: o mataba a su marido o él moría. La mujer se quedaría con el que sobreviviera. Destaca constantemente la fiereza de la mujer como el motivo que le empujó a hacer lo que hizo. Los dos hombres empiezan a luchar, y él mata al samurái con la espada. Cuando se dio cuenta, la mujer ya había huido.

b) Versión de la mujer. La siguiente en declarar en el juicio es la mujer del Samurái. Llora en todas sus declaración y muestra compasión por su marido constantemente. A través de un flashback vemos en esta versión ofrecida por la mujer cómo, tras sufrir su violación, su marido le mira con frialdad. Llora constantemente sintiéndose humillada y pide a su marido que la mate, pero sin saber explicar cómo, dice que encontró su daga en el cuello de su mujer. Había matado a su marido. Ella cuenta cómo, después de esto, intentó suicidarse tirándose al río sin conseguirlo.

c) Versión del samurái muerto a través de una médium. Tal vez sea la vuelta al pasado más espectacular de la película desde el punto de vista visual. Con este flashback el marido cuenta a través de una médium cómo después de que el bandido abusara de su mujer, ella fue quien pidió a Tajomaru que le matara. El bandido, conmocionado por las palabras, coge a la mujer y le pregunta al samurái si quiere que la mate o que la deje en libertad. Ella se escapa corriendo y el ladrón libera al marido. El samurái llora desconsolado, coge la daga de su mujer que estaba en el suelo, vaga por el bosque, y se quita la vida. Dice que, tras morir, alguien se acercó a él y le quitó la daga de su pecho.

d) Segunda versión del leñador. La narración de los hechos vuelve de nuevo al templo de Rashomon, al tiempo presente, y el leñador matiza la declaración del marido y dice que no era un daga, si no que el hombre murió por una espada. El peregrino le pregunta por qué no lo había dicho en el juicio, y el leñador contesta que no quería involucrarse en ese momento. Es aquí cuando aparece última versión de los sucesos del bosque. En este última flashback volvemos al bosque y vemos cómo el ladrón le suplica a la mujer, tras 
violarla, que se case con él. En esta versión del leñador, la mujer libera a su marido y les dice, fuera de sí, que van a tener que luchar como hombres por ella. Sin embargo, el marido rechaza pelear por su mujer, pero ella insiste en que "una mujer ama apasionadamente al hombre que la ha conseguido por la fuerza de una espada". Tras una gran lucha, el bandido mata al samurái. La mujer escapa y el bandido se va con la espada.

En la siguiente tabla se exponen las cuatro últimas versiones de los testigos, diferenciando quién cuenta la historia, quién es el asesino, cuál es el motivo del crimen y el desenlace (Véase tabla 2):

Tabla 2. Variaciones en la historia dependiendo de la versión

\begin{tabular}{|c|c|c|c|}
\hline $\begin{array}{l}\text { QUIÉN CUENTA } \\
\text { LA HISTORIA }\end{array}$ & $\begin{array}{l}\text { QUIÉN MATA AL } \\
\text { SAMURAI }\end{array}$ & $\begin{array}{l}\text { RAZÓN QUE HA } \\
\text { MOTIVADO LA } \\
\text { MUERTE }\end{array}$ & DESENLACE \\
\hline $\begin{array}{l}\text { VERSIÓN } \\
\text { TAJUMARU }\end{array}$ & Tajumaru & $\begin{array}{l}\text { Empujado por la } \\
\text { mujer del samurái }\end{array}$ & $\begin{array}{l}\text { Él mata al samurái } \\
\text { y la mujer huye }\end{array}$ \\
\hline VERSIÓN MUJER & La mujer & $\begin{array}{l}\text { Empujada por el } \\
\text { odio que mostró } \\
\text { su marido hacia } \\
\text { ella al ser abusada } \\
\text { por Tajomaru }\end{array}$ & $\begin{array}{l}\text { Ella mata al } \\
\text { samurái e intenta } \\
\text { suicidarse sin } \\
\text { éxito después }\end{array}$ \\
\hline $\begin{array}{l}\text { VERSIÓN } \\
\text { SAMURAI } \\
(\text { MEDIUM) }\end{array}$ & $\begin{array}{l}\text { El propio Samurái } \\
\text { se quita la vida }\end{array}$ & $\begin{array}{l}\text { La deshonra de } \\
\text { ver cómo su mujer } \\
\text { le pide al ladrón } \\
\text { que le mate a él }\end{array}$ & $\begin{array}{l}\text { El propio samurái } \\
\text { acaba con su vida } \\
\text { con la daga de su } \\
\text { mujer, y alguien se } \\
\text { la quita después } \\
\text { de su pecho }\end{array}$ \\
\hline $\begin{array}{l}\text { SEGUNDA } \\
\text { VERSIÓN } \\
\text { LEÑADOR }\end{array}$ & Tajomaru & $\begin{array}{l}\text { La mujer empuja a } \\
\text { los dos hombres a } \\
\text { que luchen por } \\
\text { ella }\end{array}$ & $\begin{array}{lr}\text { El samurái muere } \\
\text { por la espada de } \\
\text { Tajomaru. } & \text { La } \\
\text { mujer huye } & \text { y } \\
\text { Tajomaru se } & \text { va } \\
\text { con la espada } & \end{array}$ \\
\hline
\end{tabular}

Se observa, por tanto, cómo todas las versiones difieren. Sólo hay dos hechos en la que todos coinciden: el samurái ha muerto y la mujer ha sido violada. No obstante, todos los personajes mienten conscientemente para engañar a quienes deben enjuiciarles: el bandido quiere recibir una condena menos severa, la mujer no quiere inculparse, el marido muerto tiene un honor que defender y el leñador está encubriendo un posible robo de una espada. En consecuencia, los narradores juegan con la verdad con el fin de 
proteger y reforzar su propia imagen. Las declaraciones son incoherentes en su conjunto, a la vez que insinceras individualmente. Por lo tanto, el filme no proporciona la clave de interpretación para saber quién dice la verdad. La ambigüedad es persistente. Aunque algunos estudiosos han intentado resolver el misterio del asesinato de Rashomon apuntado al leñador como el verdadero asesino del samurái, por tener un gran motivo para mentir ${ }^{27}$. Pero es algo que no parece importar a Kurosawa ya que ni siquiera sabemos la resolución oficial del juicio que hemos estado presenciando.

El filme es sobre una violación y una muerte, pero sobre todo, de la manipulación de esos eventos a través de las narraciones interesadas, más que de la verdad sobre lo ocurrido. A Kurosawa le interesaba destacar una lectura moral de este filme, y lo ha explicado de la siguiente manera ${ }^{28}$ :

"Los seres humanos son incapaces de ser honestos con ellos mismos. No pueden hablar sobre ellos sin enaltecerse. Este guión refleja a estos personajes que no puede vivir sin mentir para hacerse sentirse mejor personas de las que realmente son. También enseña esa pecaminosa necesidad por adular la falsedad más allá de la tumba- incluso el hombre que muere no puede renunciar a sus mentiras mientras habla a través del médium. El egoísmo es un pecado que el ser humano lleva consigo desde su nacimiento; es el más difícil de redimir" (Traducción propia).

Por tanto, Kurosawa destaca cómo lo que lleva a los hombres a destruirse entre ellos es el egoísmo, uno de los pecados más difíciles de redimir. La compasión y la vuelta a las acciones virtuosas son, como veremos a continuación, algunas claves para liberar a los hombres de esa atadura.

\section{3 ÚLTIMA ESCENA Y ¿REDENCIÓN FINAL?}

Se observa cómo la utilización del multiperspectivismo acompañado por los saltos en el tiempo en este filme ofrece una sugerente reflexión a la audiencia sobre la incapacidad de conocer la verdad a través de la narración de historias insinceras y cuán subjetivos pueden ser los recuerdos de quien habla. Tras escuchar esas declaraciones y tras participar en el fascinante juego audiovisual en el que nos envuelve Kurosawa, el espectador se ve incapacitado para dilucidad qué es lo que ha ocurrido realmente. Se ha especulado mucho sobre quién es realmente el asesino de la película, sin alcanzar respuesta. Algunos lo llaman el "Gran Misterio del Asesinato de Rashomon". Gran misterio porque no puede haber solución alguna. Las declaraciones son incongruentes, todos los personajes tienen motivos para mentir y la película no da las claves para solucionarlo. Es un auténtico misterio sin resolver.

${ }^{27}$ Cfr. RICHIE, D. (1970): “Rashomon”, en The films of Akira Kurosawa. Berkeley: University of California Press, pp. 7080 .

${ }_{28}$ Cfr. KUROSAWA, A. (1982): Something like an Autobiography. New York: Alfrend A. Knopf, p. 183. 
Estamos ante una película que pone de relieve la incapacidad de conocer la verdad que ha sido contada por unos hombres movidos por pasiones mundanas y el egoísmo. La última escena, es tal vez la más desconcertante para la crítica. Como hemos visto, algunos críticos especializados la consideran totalmente separada e inconexa respecto a la historia central. Sin embargo, a mi juicio, es la pieza suelta y necesaria del engranaje que, aunque no resuelve el misterio desde un plano cognitivo, si aporta soluciones al problema planteado en la película desde un plano moral, la única posible. Recordemos esta última escena.

Sigue lloviendo. El leñador acaba de contar su segunda versión de lo ocurrido para no inculparse en el robo de la espada del Samurái. El peregrino no cree tampoco esta segunda versión. De repente, en un lado del templo se oye a un bebé llorar. Ha sido abandonado por sus padres; y el peregrino se acerca para robar el kimono que envolvía al niño. El leñador le acusa de ser un egoísta por robar esa prenda a lo que el peregrino responde: "Si no eres egoísta, no puedes sobrevivir", y le echa en cara que él también sólo piensa en él porque, aunque quiera ocultarlo, robó la daga de la mujer. El leñador se paraliza conmocionado. Sigue lloviendo fuerte. El peregrino se va con el kimono.

Silencio. El leñador y el sacerdote se quedan solos en el templo, pensativos. La cámara enfoca un gran plano general, quedando ellos como si fueran insignificantes hormigas en un mundo desolado, egoísta, sin esperanza. Es entonces cuando el leñador le dice al sacerdote que quiere quedarse con el niño. Le explica que tiene ya seis hijos y que uno más no le supondrá mucho. El sacerdote, aunque desconfía al principio, le entrega el niño y le dice sonriendo: "Gracias. Creo que ahora puede seguir creyendo en los hombres". Se despiden. Ha dejado de llover. Ha salido el sol por primera vez en toda la película. La cámara sigue al leñador que se aleja del templo sonriendo.

La última escena, como acción final que da sentido pleno a toda la película, aunque no es concluyente, da un halo de esperanza al mostrar la posible redención de esos fallos del hombre a través de acciones virtuosas. No es concluyente porque el espectador desconoce si el leñador dice la verdad, si tiene hijos o si realmente va a cuidar del bebé abandonado como dice. Sin embargo, el final de la película admite la posibilidad de que el leñador se arrepienta de sus errores y realice una acción bondadosa movida por la compasión, y que por ello, sea de alguna manera perdonado. No es baladí, pienso, que sea el sacerdote quien tenga la última palabra para agradecerle su buen acto con respecto al niño. Como le dice el sacerdote en la última frase, puede recobrar no sólo la fe en él, sino también en la de humanidad.

Por lo tanto, el que no se puede resolver el "Gran misterio del Asesinato de Rashomon" se debe a que el ser humano es débil y no puede evitar mentir por su naturaleza y egocentrismo. La única solución posible en este cuadro de pasiones fatales viene a través de la compasión y de las acciones bondadosas. A través de la rectificación de todos los errores que hemos presenciado en la pantalla con esos personajes corruptos y que conducen inevitablemente a realidades sin sentido, ilógicas, incomprensibles. 


\section{A MODO DE CONCLUSIÓN: REFLEXIONES EN TORNO AL CONOCIMIENTO DE LA VERDAD Y LAS "NARRACIONES MENTIROSAS"}

El análisis de la película Rashomon a través del concepto de tiempo y perspectiva nos ha revelado interesantes cuestiones que invitan al espectador de todos los tiempos a reflexionar sobre su propia existencia y que subraya la profundidad, humanismo y actualidad de esta obra de Kurosawa:

Primero, la película resalta la imposibilidad de conocer la verdad de unos hechos a través de unas narraciones mentirosas. Es decir, no niega la existencia de la verdad. De hecho, en ningún momento se cuestiona si el samurái ha muerto y si su mujer ha sido violada. Todas las declaraciones coinciden en esto. Los hechos han ocurrido y, por tanto, hay una verdad objetiva. Lo que ocurre es que los relatos aportados sobre este hecho no se adecuan a la realidad de los acontecimientos porque el hablante los ha modificado en su beneficio propio. Todas las narraciones expuestas están manipuladas. Los relatos proporcionados a través del multiperpectivismo son insinceros individualmente $\mathrm{y}$, en consecuencia, incoherentes en su conjunto. Todos, como se ha apuntado ya, tiene una razón para mentir. Además, la película no ofrece ninguna clave desde el punto de vista poético para comprender la verdad de lo ocurrido. Por lo tanto, se puede afirmar que es imposible conocer la verdad si el que habla miente. Lo interesante desde el punto de vista del lenguaje audiovisual es que si solamente hubiéramos escuchado una de las declaraciones, nosotros como espectadores no hubiéramos detectado que eran mentira. Cada una de las declaraciones es coherente y verosímil individualmente, y sólo empezamos a cuestionar su veracidad cuando se nos ofrecen otras versiones y detectamos que todas ellas son incongruentes en su conjunto. Por lo tanto, la posibilidad de mostrar esta situación solamente se puede conseguir a través del uso del multiperspectivismo y los múltiples saltos en el tiempo.

Segundo, la película apunta directamente al egoísmo y debilidad de la naturaleza humana como explicación de la existencia de estas narraciones mentirosas y como parte de la decadencia general de la sociedad. En este contexto, las referencias trascendentales son inevitables. No es baladí que la historia central se desarrolle en las ruinas de un gran templo y que uno de los personajes atormentados por este desconcierto sea un sacerdote. El peregrino es la cara cínica y más realista en la película: "Bueno, los hombres son sólo hombres. Por eso se que mienten. No pueden decir la verdad, ni siquiera a ellos mismo". El sacerdote, más trascendente, explica que "Los hombres son débiles, y por eso miente, incluso a sí mismos". Por lo tanto, la película apunta a esa inevitable capacidad del hombre para mentir, algo que va unido a su propia naturaleza y que trae como consecuencia una sociedad en la que todos desconfían de todos. El sacerdote, presa de la incertidumbre, llega a afirmar que "si los hombres no dicen la verdad y no confían el uno con el otro, entonces la tierra se ha convertido en una especie de infierno". 
Tercero, la única manera de recobrar el equilibro exige una vuelta a la sinceridad en el relato. La película no refleja la incapacitad del hombre para conocer la verdad a través de las narraciones, apunta necesariamente a la honestidad del emisor para que esto ocurra. La verdad se conoce, de hecho, a través del relato. Como apunta MacIntyre: "porque vivimos narrativamente nuestras vidas y porque entendemos nuestras vidas en términos narrativos, la forma narrativa es la apropiada para entender las acciones de los demás" 29 . Recordemos una vez más la figura del peregrino en la película. Sin alguien a quien contar la historia, los espectadores no conoceríamos la historia de Rashomon. Por lo tanto, los relatos son necesarios para conocer la verdad. La sinceridad de la narración viene tras la adecuación honesta del relato con la realidad conocida por el emisor. De tal manera que: a) el testigo directo de los hechos tiene acceso a conocer la verdad de lo ocurrido porque la verdad se puede aprehender, b) también puede transmitir esa verdad a través de un relato ya que la verdad puede ser narrativamente transmitida, c) el emisor puede conocer la verdad a través de la narración si se restaura este orden. Indispensable para que haya comunicación: la sinceridad y honestidad del emisor. Por lo tanto, la solución al problema de las "narraciones mentirosas" de Rashomon se nos revela en un plano moral a través del arrepentimiento de los propios errores y la realización de acciones bondadosas, la única manera de poder validar esas narraciones.

\section{BIBLIOGRAFÍA}

- AKUTAGAWA R.: “Rashomon y otros cuentos”. Buenos Aires, 2003. Libros en Red.

- KUROSAWA, A.: Something like an Autobiography. New York. Alfrend A. Knopf. 1982.

- MACINTYRE, A.: Tras la virtud. Barcelona. 1987. Crítica.

- RICHIE, D.: “Rashomon”. En The films of Akira Kurosawa. Berkeley. 1970. University of California Press.

- YOSHIMOTO, M.: Kurosawa Film Studies and Japanese Cinema. Durham. 2000. Duke University Press.

\section{CRÍTICAS EN LA PRENSA}

- BEAUFORT, J. The Christian Science Monitor. 2 de enero de 1952.

- CROWTHER, B., The New York Times. 27 de diciembre de 1951.

${ }^{29}$ Cfr. MACINTYRE, A. (1987): Tras la virtud. Barcelona: Crítica, p. 269. 
- FARVER, M.; The Nation. 12 de enero de 1952.

- GRIFFITH, R. Saturday review. 12 de enero de 1952.

- McCARTEN, J., The New Yorker. 29 de diciembre de 1951.

- MERCIER, P., Cahiers du Cinéma. 24 de junio de 1953.

The New York Times

- "Venice Festival in Retrospect". The New York Times: 15 de septiembre de 1957

- "Hollywodd new look. Rashomon altered in Time. The New York Times.19 de enero de 1964.

- “Japan's Emperor of Film”, The New York Times. 29 de octubre de 1989.

- “Jottings on Japan's Screen Scene”. The New York Times: 30 de junio de 1954.

- “Look for me in my film”. The New York Times: 27 de junio de 1982

- "Rashomon returns, probing reality anew". The New York Times, 20 de marzo de 1988.

- "Rashomon". Time. 7 de enero de 1952.

- “Screen: Change in Scene". The New York Times, 23 de noviembre de 1961.

- “Screen: Hidden Fortress' From Japan". The New York Times. 24 de enero de 2962.

- "Screen: Kurosawa's Lower Depths". The New York Times. 10 de febrero de 1962.

- "When facts don't up to the Truth". The New York Times. 25 de mayo de 1986.

The Washington Post

- "Akira Kurosawa and his mountain of memories". The Washington Post. 14 de septiembre de 1990.

- “Film Award Helps Japan Industry". The Washington Post: 30 de enero de 1952.

- "Kurasawa, Samurai of the Cinema". The Washington Post. 4 de julio de 1982.

- "The Setting Sun of Akira Kurosawa". The Washington Post. 28 de diciembre de 1993.

The Hudson Review

- "Rashomon and the fith Witness", The Hudson Review, 5(3), 1952. 


\section{ANEXO 1: FICHA DE LA PELÍCULA}

Productor: Jingo Minoru (Daiei production)

Director: Akira Kurosawa

Guión: Shinobu Hashimoto y Akira Kurosawa. Basado en dos relatos de Ryunosuke Akutagawa (Rashomon y En el bosque)

Fotografía: Kazuo Miyagawa

Iluminación: Kenichi Okamoto

Dirección artística: So Matsuyama

Música: Fumio Hayasaka

Reparto: Toshiro Mifune (Tajomaru, el bandido), Masayuki Mori (Takehiro, el Samurái), Machiko Kyo (Masago, su mujer), Takashi Shimura (el leñador), Minoru Chiaki (el sacerdote), Kichijiro Ueda (peregrino), Daisuke Kato (agente de policía) Fumiko Homman (la médium).

Distribución: Daiei

Duración: 88 minutos

Estreno: 25 de agosto, 1950.

Estreno en Estados Unidos: 26 de diciembre de 1951. 